Grand Valley State University

ScholarWorks@GVSU

4-2009

\title{
Differential Effects of a Tier Two Behavior Intervention Based on Function of Problem Behavior
}

\author{
Kent McIntosh \\ University of British Columbia \\ Amy L. Campbell \\ Grand Valley State University, campbeam@gvsu.edu \\ Deborah R. Carter \\ Boise State University \\ Celeste R. Dickey \\ University of Oregon
}

Follow this and additional works at: https://scholarworks.gvsu.edu/psy_articles

Part of the Psychology Commons

\section{ScholarWorks Citation}

McIntosh, Kent; Campbell, Amy L.; Carter, Deborah R.; and Dickey, Celeste R., "Differential Effects of a Tier Two Behavior Intervention Based on Function of Problem Behavior" (2009). Peer Reviewed Articles. 42. https://scholarworks.gvsu.edu/psy_articles/42

This Article is brought to you for free and open access by the Psychology Department at ScholarWorks@GVSU. It has been accepted for inclusion in Peer Reviewed Articles by an authorized administrator of ScholarWorks@GVSU. For more information, please contact scholarworks@gvsu.edu. 


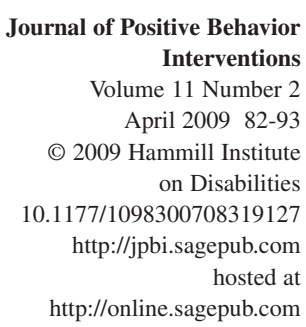

\author{
Kent McIntosh \\ University of British Columbia \\ Amy L. Campbell \\ Grand Valley State University, Allendale, Michigan \\ Deborah Russell Carter \\ Boise State University, Idaho \\ Celeste Rossetto Dickey \\ University of Oregon, Eugene
}

\begin{abstract}
The purpose of this study was to investigate the effectiveness of a tier two daily behavior card intervention and differential effects based on function of problem behavior. The participants were 36 elementary school students nominated for additional intervention beyond universal School-Wide Positive Behavior Support. Measures included standardized behavior rating scales and rate of office discipline referrals before and after 8 weeks of intervention. A multivariate analysis of variance was used, and results showed statistically significant differences in response to intervention based on teacheridentified function of problem behavior. Results are discussed in terms of considering function of behavior in selecting tier two interventions and implementing a three-tier response to intervention model.
\end{abstract}

Keywords: behavioral assessment; functional assessment; challenging behavior(s); positive behavior support(s)

$\mathrm{T}$ 2004 reauthorization of the Individuals with Disabilities Education Act (Individuals with Disabilities Education Improvement Act, 2004) allows educational agencies to use a response to intervention (RTI) model for identifying students under the category of specific learning disability. In contrast to previous models of special education eligibility that relied on results of standardized measures of cognition and academic achievement, RTI relies on the continuous monitoring of student progress while providing multiple tiers of prevention and intervention. Although the specific components of RTI vary by implementation context, the RTI process generally includes the following: (a) screening all students to identify who may benefit from additional support, (b) implementing evidence-based interventions, (c) providing a continuum of intervention through multiple tiers of intensity (i.e., primary, secondary, and tertiary), (d) continuously monitoring all student progress, and (e) examining student progress data to make special education eligibility decisions (Fuchs, Mock, Morgan, \& Young, 2003; Gresham, VanDerHeyden, \& Witt, 2005).
Although the majority of research and scholarly discussion has focused on using RTI models for academic concerns, several researchers have proposed a similar model for social behavior problems (Eber, Sugai, Smith, \& Scott, 2002; Fairbanks, Sugai, Guardino, \& Lathrop, 2007; Gresham, 1991; Sugai, Horner, et al., 2000). In the field, more than 6,600 schools across North America are

Authors' Note: This research was supported in part by U.S. Department of Education Grants No. H324D020031 and Q215E050001. Opinions expressed herein do not necessarily reflect the policy of the Department of Education, and no official endorsement by the department should be inferred. The authors are grateful for the assistance provided by the Bethel School District Leadership Team, including Monica Bounds, Drew Braun, Remie Calalang, Carl Cole, Ginger Kowalko, and Margaret Lathrop. The authors would also like to thank Aaron Barnes, Olivia Bradway, Chad Harrison, Nicole Roberts, Billie Jo Rodriguez, and Jessica Swain-Bradway for their assistance.

Please address correspondence to Kent McIntosh, University of British Columbia, Educational and Counselling Psychology and Special Education, 2125 Main Mall, Vancouver, BC Canada V6T 1Z4; e-mail: kent.mcintosh@ubc.ca.

Action Editor: Don Kincaid 
implementing a three-tier RTI model to support student social behavior (Bradley, Doolittle, Lopez, Smith, \& Sugai, 2007; Horner, Sugai, Todd, \& Lewis-Palmer, 2005). Three-tier models provide a proactive continuum of support, in place for all students in a school (O'Shaughnessy, Lane, Gresham, \& Beebe-Frankenberger, 2003; Simmons et al., 2002; Sugai, Horner, \& Gresham, 2002; Vaughn, Linan-Thompson, \& Hickman, 2003). Three-tier RTI models focus not only on the remediation of problems but also on prevention. Thus, a continuum of behavior support ranges from universal strategies to prevent the occurrence of problems for all students in the school, to highly structured, individualized interventions for students who display severe skill deficits. H. M. Walker and colleagues (1996) advanced a three-tier continuum of behavior support based on an established public health model delineating primary, secondary, and tertiary prevention (Gordon, 1983; Simeonsson, 1994). Following this logic, school personnel implement a proactive, universal system for all students. The tier one (primary prevention) system is a generic set of interventions intended to provide adequate support for $80 \%$ to $85 \%$ of the school population. A tier two (secondary prevention) system is put in place to support students who are at risk for developing more serious problem behaviors and do not respond to the universal system alone. This is typically successful for $10 \%$ to $15 \%$ of the school population. Finally, a highly individualized tier three (tertiary prevention) system is implemented for students who display the most serious problem behaviors and do not respond to either tier one or tier two interventions. This is typically needed for $3 \%$ to $5 \%$ of the student population. Decision rules to move students up and down tiers are based on need for support, which is determined by continuous monitoring of student progress. Students will continue to move up the tiers until an intervention is effective. If the student requires a resource-intensive program that includes specially designed instruction (i.e., tier three), he or she may qualify for special education services.

An example of a promising three-tier RTI model for social behavior is School-Wide Positive Behavior Support (SWPBS; Colvin, Kame'enui, \& Sugai, 1993; Horner et al., 2005; Sugai, Horner, et al., 2000). The SWPBS approach involves selecting and implementing evidence-based interventions at each tier and using school-wide and individual data to provide and improve support for students. Fairbanks and colleagues (2007) examined a SWPBS three-tier RTI approach at the classroom level. Within an existing school-wide intervention (universal SWPBS), teachers and behavior consultants implemented a tier one classroom management intervention for all students and identified students who did not respond to the universal intervention through office discipline referrals. These students were provided with a tier two intervention (the intervention examined in this study). Students at tier two were monitored through daily points earned and direct observation. Those who did not respond to the tier two intervention were then provided with a tier three intervention, individualized functionbased support (Crone \& Horner, 2003).

\section{Tier Two Interventions}

Within the three-tier RTI model, tier two interventions have received less research scrutiny than tier one or three interventions. This level of support is intended for students who need more support than the universal system but may not require an intensive individualized intervention. Tier two interventions share a number of critical features. Typically, these are ongoing programs that serve a varying number of students at any given time. The support is provided similarly for all students-this makes the interventions cost-effective and efficient for individual school personnel to implement (March \& Horner, 2002). To be efficient in delivery, these interventions should be readily available for referred students, require little assessment prior to implementation, require few additional resources, and take no more than 10 minutes per day of classroom teacher time (Crone, Horner, \& Hawken, 2003). In addition, the intervention must be cost-effective so that it can support multiple students with few resources. Examples of tier two behavior interventions include daily report cards, social skills training groups, anger management programs, and homework clubs (Hawken \& Horner, 2003).

\section{Check-In/Check-Out}

One commonly used tier two intervention is CheckIn/Check-Out (also known as the Behavior Education Program; Crone et al., 2003). Check-In/Check-Out is a manualized, tier two intervention designed to decrease problem behavior and increase prosocial behavior through direct behavior ratings of student performance. The intervention is designed to (a) add structure to the school day, (b) provide regular opportunities for feedback, and (c) cultivate a relationship with an adult mentor in school. In addition to the evidence for direct behavior ratings in general (see Chafouleas, RileyTillman, \& McDougal, 2002), Check-In/Check-Out, in particular, has been the focus of a number of intervention studies demonstrating its effectiveness in reducing problem behavior and increasing academic engaged time for students (Fairbanks et al., 2007; Filter et al., 2007; Hawken, 2006; Hawken \& Horner, 2003; Hawken, 
McLeod, \& Rawlings, 2007; March \& Horner, 2002; Todd, Campbell, Meyer, \& Horner, 2008).

The Check-In/Check-Out program is a multicomponent intervention that includes (a) a brief (less than 5 minutes) daily meeting with an adult mentor at the start of the school day (the "check-in"), (b) brief ratings and feedback from teachers at the start and end of each period, (c) a debriefing with the mentor at the end of the day (the "checkout"), and (d) a school note home providing information to parents/guardians. The check-in is intended to provide students with a daily behavior rating card, engage the student in a positive interaction, and provide precorrections and encouragement. The in-class ratings are designed for teachers to prompt expected behavior and give feedback to the students while rating their behavior in predefined positive behaviors, usually the school-wide expectations (e.g., "Safe, Responsible, and Respectful"). At the check-out, the students review their behavioral performance with the mentor, total the points earned, and take the card home for a parent/guardian signature. Students earn points toward small tangible items or social privileges, such as school supplies or lunch with the mentor.

\section{Current Concerns With Regard to Tier Two Interventions}

A tier two intervention represents a precarious balance between the other tiers. For tier one, the evaluation question is simple: Is the student responding to an evidencebased, fully implemented universal intervention? If the answer is no, the student moves up the tiers. For tier three, it is also relatively straightforward: Is the student responding to the individualized intervention? If the answer is no, additional assessment and modification of the plan are indicated. Because tier two lies between these tiers, the question is more complex. The initial question of RTI is the same, but if the answer is no, there exists a further question: Is the lack of response due to an insufficient intensity of intervention (i.e., the student requires a tier three intervention) or a poor match to the student's needs (i.e., the student requires a different tier two intervention)? Answering this question incorrectly could lead to an improper special education eligibility decision or the delay of needed intensive services (Fuchs et al., 2003).

Several pressing concerns about the three-tier model have not been addressed in the current research literature. For example, it is unknown whether tier two interventions should be modified to the individual student's needs before moving up to the tier three level of support (essentially adding another tier of slightly individualized support). Modifications could provide students with efficient support in the least restrictive environment, but adding an additional step to RTI may also stall the provision of needed services. In addition, it is unknown whether just a single tier two intervention is sufficient for the entire school or if multiple options are necessary.

One particularly important dimension of behavior to consider in this debate is function of problem behavior. Decades of research support the use of functional behavior assessment as an intervention planning tool for students exhibiting problem behavior (Carr, Horner, et al., 1999; Lane, Umbreit, \& Beebe-Frankenberger, 1999; McIntosh, Brown, \& Borgmeier, in press). Although some researchers in the past have criticized its utility (Gresham, 2003; Sasso, Conroy, Stichter, \& Fox, 2001), recent research has shown that interventions that do not address the function of problem behavior are unlikely to be successful in reducing moderate to severe problem behavior (Carter \& Horner, 2007, in press; Filter \& Horner, in press; Ingram, Lewis-Palmer, \& Sugai, 2005; March \& Horner, 2002; Newcomer \& Lewis, 2004). Therefore, a key consideration when assessing an RTI model of behavior support is whether function of problem behavior moderates the response to tier two interventions.

Some recent studies have examined the effect of function on two commonly used tier two behavior interventions. Carter and Horner (2007, in press) completed studies examining the effectiveness of adding functionbased support to First Step to Success (H. M. Walker et al., 1998), a standardized tier two intervention designed to provide adult attention and group contingencies for appropriate behavior. Carter and Horner modified the intervention for students whose behavior was not maintained by adult attention. Their results provide evidence that adding function-based support to tier two interventions improves student response to intervention. March and Horner (2002) provided initial descriptive evidence that response to a Check-In/Check-Out intervention was moderated by function of problem behavior. The authors implemented Check-In/Check-Out for 24 students in grades 6 through 8 and monitored the number of office discipline referrals received. Functional behavior assessment interviews indicated that $69 \%$ of students whose behavior was maintained by adult or peer attention had decreases in rates of referrals, and only $27 \%$ of students with escape-maintained behavior had such decreases. Although results provide an indication of differential responses to Check-In/Check-Out based on function, the dependent variable used (office discipline referrals) does not by itself provide an adequate test of intervention effectiveness. In sum, all three of these studies provide some preliminary evidence that function may play a key role in response to tier two interventions, and schools may need to provide multiple tier two interventions (addressing multiple functions) or adapt existing interventions to address function. 


\section{Purpose of This Study}

This study was designed to address concerns about differential effectiveness of a commonly used tier two intervention based on function in an RTI model. The effectiveness of Check-In/Check-Out was assessed by measuring levels of behavioral functioning before and 8 weeks after implementation. The authors used a standardized behavior rating scale with strong psychometric evidence in addition to existing office discipline referrals and a semistructured interview protocol to generate hypothesized function of problem behavior. Specifically, the following research question was assessed: Is there an interaction between teacher-identified function of problem behavior and effects of Check-In/Check-Out on ratings of problem behavior, ratings of prosocial behavior, and office discipline referrals? In other words, to what extent does function of problem behavior moderate the effectiveness of Check-In/Check-Out?

\section{Method}

\section{Setting}

The setting for the study was six public elementary schools in a school district in the Pacific Northwest region of the United States. In the year the study took place (2005-2006 school year), total district K-12 enrollment was 5,410 students. The district's ethnic composition was 3\% African American, 3\% Asian American/Pacific Islander, 78\% European American, 14\% Latino/a, and 3\% Native American/Native Alaskan. The percentage of schools in the district qualifying for Title I services was $88 \%$, with the percentage of children receiving free or reduced lunch at 53\% (ranging from 32\% to 73\%).

The district has an ongoing, 12-year SWPBS initiative, and all schools participating in the study had a tier one SWPBS system in place at above $80 \%$ mean implementation, measured by the School-wide Evaluation Tool (Sugai, Lewis-Palmer, Todd, \& Horner, 2001), a fidelity of implementation measure with evidence of sufficient validity and reliability (Horner et al., 2004). Student outcome data also indicated effective tier one systems at each school, as all elementary schools' percentages of students receiving 0 or 1 yearly discipline referrals were above $90 \%(M=94 \%)$, above criteria for effective tier one programs (H. M. Walker et al., 1996) and recent national averages for schools implementing SWPBS (Horner et al., 2005). In addition, the district has an ongoing intensive student systems initiative, designed to support students with severe behavior challenges (LewisPalmer, Bounds, \& Sugai, 2004). Each school also met criteria for an adequate system of behavior support at tiers two and three, as measured by the Individual Student Systems Evaluation Tool (Lewis-Palmer, Todd, Horner, Sugai, \& Sampson, 2003). Finally, five of the six participating schools had an existing Check-In/CheckOut intervention in place at the time of the study.

\section{Participants}

Participants in the study were students who were nominated by their classroom teachers for the Check-In/CheckOut intervention based on their levels of problem behavior and perceived need for support beyond universal SWPBS (lack of response to the tier one intervention). Initially, 40 students participated in the study, but some students had identified functions that were rare in this sample, including escape social interaction $(n=2)$, obtain tangible item $(n=1)$, and multiple functions $(n=3)$. Due to the inherent dangers of using a small sample to assess group differences, these six students were not included in the analyses, bringing the final $n$ down to 34 . This final group included students whose functions were generated by the Functional Assessment Checklist for Teachers and Staff (FACTS; March et al., 2000) as obtain adult/peer attention $(n=18)$ or escape academic task $(n=16)$. Participants were enrolled in grades 1 through $5(M=2.78)$ and ranged in age from 6 to 11 years. There were 28 male and 6 female students. The ethnic backgrounds of the students were as follows: 3\% African American, 88\% European American, 6\% Latino/a, and 3\% Native American/Native Alaskan, indicating a slight overrepresentation of European American and underrepresentation of Latino/a students.

\section{Measures}

Teacher-identified function of problem behavior. For the purposes of this study, the function of problem behavior was assessed through the FACTS. The FACTS is a face-to-face teacher/staff semistructured interview form that is used to identify a problem behavior and generate a hypothesized function of problem behavior. The outcomes of the FACTS include a hypothesized summary statement of problem behavior, including an operational definition of the primary problem behavior, antecedents and consequences of problem behavior, and a function maintaining problem behavior, such as obtaining adult or peer attention, tangible items/activities, or sensory stimulation, or escaping academic tasks, social interactions, or sensory stimulation. There is moderate validity and reliability information supporting the use of teacher interviews in general (Beaver \& Busse, 2000; Carr, Langdon, $\&$ Yarbrough, 1999), and the FACTS itself has been shown 
to possess evidence of sufficient validity, reliability, and treatment utility when administered by trained graduate students (as in this study). Two research studies provide the following technical adequacy data: test-retest reliability for function of .92 and agreement on function with direct observation results in $96 \%$ of cases (Borgmeier, 2003; McIntosh, Borgmeier, et al., 2008).

Problem behavior ratings. Levels of behavior were measured through the Behavior Assessment Scale for Children 2 (BASC-2; Reynolds \& Kamphaus, 2004). The BASC-2 is a standardized, norm-referenced behavior rating scale for assessing levels of problem behavior in school-aged students. The BASC-2 was selected because of its recent revision, its psychometric properties, and its updated, representative normative group. The measure also contains four validity indices to control for biased responding. The form used in this study was the BASC-2 Teacher Report Scale-Child Form, designed to rate the behavior of students aged 6 to 11 years. Composite scales for the BASC-2 are reported as $T$-scores, with a mean of 50 and a standard deviation of 10 . To measure level of problem behavior, the authors used the Behavioral Symptoms Index (BSI), a composite scale made up of the following subscales: hyperactivity, aggression, depression, attention problems, atypicality, and withdrawal. The BASC-2 test manual reports the following technical adequacy means for this composite scale: alpha reliability, .97 ; test-retest reliability, .94; and interrater reliability, .64.

Prosocial behavior ratings. To measure level of prosocial behavior, the authors used the BASC-2 Teacher Report Scale-Child Form Adaptive Scale, a composite scale made up of the following subscales: adaptability, social skills, leadership, study skills, and functional communication. The BASC-2 test manual reports the following technical adequacy means for this composite scale: alpha reliability, .97; test-retest reliability, .89; and interrater reliability, .61.

Office discipline referrals. Office discipline referrals (ODRs) are school-based forms designed to document serious behavioral incidents and track individual student behavior (Sugai, Sprague, Horner, \& Walker, 2000). School staff issue ODRs to students for serious behavioral violations, including fighting, vandalism, harassment, or noncompliance. ODRs have been shown to possess sufficient construct validity as a behavioral measure (Irvin, Tobin, Sprague, Sugai, \& Vincent, 2004) and adequate concurrent validity with standardized behavior rating scales (McIntosh, Campbell, Carter, \& Zumbo, 2008; B. Walker, Cheney, Stage, \& Blum, 2005), and ODRs have been moderately correlated with other indirect measures of problem behavior, such as student self-report of delinquent behavior (Gottfredson \& Gottfredson, 1999). In addition, the number and type of ODRs received significantly predict a range of future outcomes, including violent events in school and dropout (Tobin \& Sugai, 1999). Predictive validity from one year to the next for middle and high school students has been documented at .54 (Gottfredson \& Gottfredson, 1999), within the reported range of some standardized behavior rating scales.

When incidents of problem behavior occur in the participating district, school personnel complete ODR forms, which are entered into the School-Wide Information System (SWIS; May et al., 2002), a Web-based ODR data system, to tally total ODRs per year. To increase the reliability of ODR data, the district conducts regular trainings on discriminating between behaviors that do and do not warrant a referral, based on definitions used in the SWIS.

\section{Procedures}

The Check-In/Check-Out intervention was implemented as described in the manual (Crone et al., 2003), with the school's tier one expectations used as the student behaviors to be rated (e.g., Safe, Respectful, Responsible) and no modification or individualization of goals or incentives. Before program implementation, the authors provided two 2-hour training sessions for school personnel and then provided monthly follow-up training sessions that stressed the critical features of the intervention and mechanisms of behavior improvement. The authors advised school administrators to identify school personnel with time at the start and finish of each day to serve as Check-In/Check-Out coordinators and mentors. In four of the schools, the school counselor served as the program coordinator and mentor for the participants. In one school, the special education teacher was the coordinator/mentor, and in the final school, an educational aide was the coordinator/mentor.

Students were referred to participate in the CheckIn/Check-Out intervention by their classroom teachers through their usual school's request for assistance and behavior assistance team process. Prior to beginning the intervention, each student received a brief training session conducted by school personnel that (a) taught the daily routines of the Check-In/Check-Out program, (b) provided examples and nonexamples of appropriate behavior in school, and (c) provided the student opportunities to practice the daily routines of the program. After training, the student began the program.

Measurement. Upon referral for behavior support and parent consent, the school notified the researchers and an 
interview with the student's classroom teacher was scheduled. The FACTS interview and the BASC-2 were administered to the teacher 1 to 5 days prior to beginning the intervention. The follow-up BASC-2 was administered approximately 8 weeks after the student began the intervention.

Fidelity of implementation. Fidelity of implementation of the Check-In/Check-Out program was measured throughout the intervention phase. The authors administered nine random, unannounced fidelity checklists, in which fidelity was measured for multiple students. These checklists measured 10 critical features of the intervention, including the student checking in and out with the mentor, the mentor providing positive feedback for using the card and contingent feedback for performance, the team monitoring student points daily, and the student taking the card home for parent feedback. The mean percentage of observed critical features in place was $94 \%$ (range $=83 \%$ to $100 \%$ ), indicating high levels of fidelity of implementation.

\section{Design}

Data analysis. The statistical analysis used was a behavioral function mixed model multivariate analysis of variance (MANOVA) repeated across time (pre and post intervention). The three dependent variables in the analysis were the BASC-2 Behavior Symptoms Index and Adaptive Scales, administered immediately before (pre score) and after 8 weeks (post score) of intervention, and extant office discipline referrals. Data queries of the SWIS database provided the number of ODRs per student for the 8-week period preceding the intervention (pre score) and first 8 weeks of the intervention (post score). These three variables served as the repeated measures and provided an index of change in behavior based on response to the intervention.

Conventional MANOVA logic holds that the tests are examined in the following order: (a) multivariate interaction effects (function by Check-In/Check-Out effects), (b) multivariate main effects (overall effects of Check-In/ Check-Out), and (c) follow-up univariate analyses (effects on each dependent variable). However, if the interaction effect is statistically significant, the main and univariate effects cannot be interpreted, and simple effects (effects for each function) should be interpreted in their place (Keppel \& Zedeck, 1989). Based on results of previous research, the authors predicted a significant interaction effect, meaning that effects would be moderated by function of problem behavior. Specifically, the authors predicted that the intervention would be more effective for students with attention-maintained behavior.

\section{Results}

Results of the data analyses are provided in Tables 1 through 3. As shown in Table 1, there was a significant multivariate interaction effect between function and Check-In/Check-Out, $F(3,30)=4.12, p<.05$. As such, the main effect was not interpretable and simple effects (pre-post effects for each group based on function) were examined. Simple effect analyses for the effects of Check-In/Check-Out for the obtain attention group (shown in Table 2) showed a statistically significant effect of Check-In/Check-Out on ratings of problem behavior, $F(1,17)=9.25, p<.01$. The effect size (in terms of Cohen's $d$ ) associated with this difference was $d=1.04$, indicating a large effect. There was a statistically significant effect of Check-In/Check-Out on ratings of prosocial behavior, $F(1,17)=8.38, p<.05$. The associated effect size was $d=.99$, indicating a large effect. There was also a statistically significant effect of Check-In/Check-Out on office discipline referrals, $F(1$, $17)=5.16, p<.05$. The associated effect size was $r=$ .78 , indicating a medium to large effect. For the escape academic task group, simple effect analyses for the effects of Check-In/Check-Out (shown in Table 3) showed a nonstatistically significant increase in ratings of problem behavior, $F(1,15)=1.91, p>.05$. The effect size was $d=.05$, indicating a negligible effect. There was a nonstatistically significant increase in ratings of prosocial behavior, $F(1,15)=1.34, p>.05$. The effect size was $d=.42$, indicating a small to medium effect. There was also a nonstatistically significant decrease in office discipline referrals, $F(1,15)=.27, p>.05$. The associated effect size was $d=.19$, indicating a negligible to small effect. These results indicate that, for students with attention-maintained behavior, implementation of Check-In/Check-Out was associated with statistically and clinically significant improvements in ratings of problem behavior, ratings of prosocial behavior, and office discipline referrals. However, for students with escape-maintained behavior, no statistically significant effects were found.

The figures provide clarity in depicting differences in response. Figure 1 shows the mean differences in ratings of problem behavior by function. As seen, there is a marked difference in response to the intervention based on teacheridentified function. The average rating of problem behavior decreased for participants with attention-maintained behavior, whereas it increased for participants with escape-maintained behavior. Figure 2 shows the mean differences in prosocial behavior by teacher-identified function. Both groups showed an increase in ratings of prosocial behavior, 
Table 1

Within-Subjects Multivariate Analysis of Variance Summary Table

\begin{tabular}{lcccc}
\hline Source & $d f$ & $F$ & $\chi^{2}$ & $p$ \\
\hline Check-In/Check-Out & 3 & $4.17 *$ & .29 & .01 \\
$\begin{array}{l}\text { Function } \times \text { Check-In/Check-Out } \\
\quad(\text { interaction effect) }\end{array}$ & 3 & $4.12 *$ & .29 & .02 \\
Error & 30 & & & \\
\hline
\end{tabular}

Note: Function $=$ Functional Assessment Checklist for Teachers and Staff-identified function of problem behavior.

$* p<.05$.

Table 2

Simple Effects Summary Table for the Effect of Check-In/Check-Out (obtain attention function only)

\begin{tabular}{lrccc}
\hline Dependent Variable & $d f$ & $F$ & $\chi^{2}$ & $p$ \\
\hline BASC-2 BSI Scale & 1 & $9.25^{* *}$ & .35 & $<.01$ \\
$\quad$ Error & 17 & $(21.69)$ & & \\
BASC-2 Adaptive Scale & 1 & $8.38^{*}$ & .33 & .01 \\
$\quad$ Error & 17 & $(10.03)$ & & \\
Office discipline referrals & 1 & $5.16^{*}$ & .23 & .04 \\
$\quad$ Error & 17 & $(1.56)$ & & \\
\hline
\end{tabular}

Note: Values in parentheses represent mean square errors. BASC-2 = Behavior Assessment Scale for Children 2 Teacher Report Scale-Child Form; BSI = Behavioral Symptoms Index.

$* p<.05 . * * p<.01$.

Table 3

Simple Effects Summary Table for the Effect of Check-In/Check-Out (escape academic task function only)

\begin{tabular}{lrccc}
\hline Dependent Variable & $d f$ & $F$ & $\chi^{2}$ & $p$ \\
\hline BASC-2 BSI Scale & 1 & 1.91 & .11 & .19 \\
$\quad$ Error & 15 & $(22.45)$ & & \\
BASC-2 Adaptive Scale & 1 & 1.34 & .08 & .27 \\
$\quad$ Error & 15 & $(14.60)$ & & \\
Office discipline referrals & 1 & .27 & .02 & .61 \\
$\quad$ Error & 15 & $(.46)$ & & \\
\hline
\end{tabular}

Note: Values in parentheses represent mean square errors. BASC-2 = Behavior Assessment Scale for Children 2 Teacher Report Scale-Child Form; BSI = Behavioral Symptoms Index.

\section{Figure 1}

Pre-Post Differences in Behavior Assessment Scale for Children 2 (BASC-2) Problem Behavior Ratings by Teacher-Identified Function of Problem Behavior

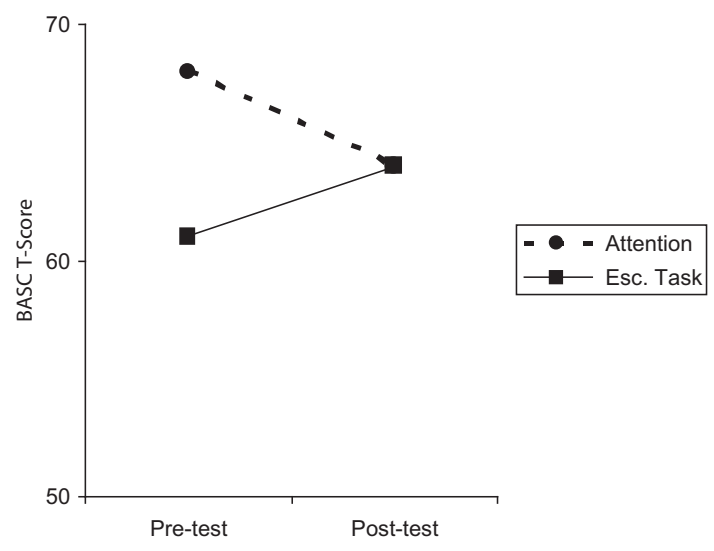

Figure 2

Pre-Post Differences in Behavior Assessment Scale for Children 2 (BASC-2) Prosocial Behavior Ratings by Teacher-Identified Function of Problem Behavior

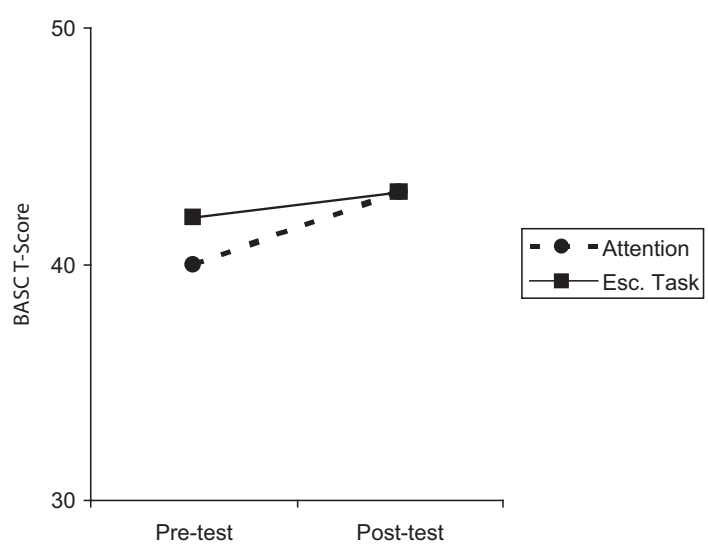

Figure 3

Pre-Post Differences in Office Discipline Referral Rates by Teacher-Identified Function of Problem Behavior

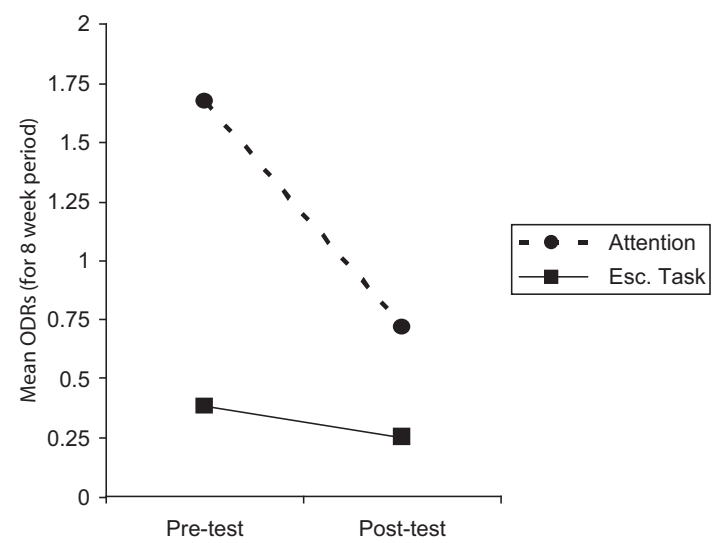


although there was a sharper (and statistically significant) increase for participants with attention-maintained behavior. Figure 3 shows the mean differences in referrals received by function. Both groups show a lower rate of referrals after intervention, although the attention-maintained group shows a steeper slope, a more than $50 \%$ decrease in referrals. These graphs were expected, given the significant interaction and simple effects seen for the participants.

\section{Discussion}

This study was designed to assess differences in response to a tier two behavior intervention based on the teacher-identified function of problem behavior. In a school district with effective tier one and tier three interventions in place, a behavioral function mixed design MANOVA repeated across time was used to assess both main effects of the Check-In/Check-Out intervention and interaction effects by function. Results showed statistically significant interaction effects, indicating differential effects of the intervention based on the hypothesized function of problem behavior. Simple effects analyses showed that there was statistically significant improvement in ratings of problem behavior, prosocial behavior, and office discipline referrals for students with attentionmaintained behavior and no significant improvement for students with escape-maintained behavior. In essence, teacher-identified function predicted the response to intervention.

Given that there were some positive effects for all students who received the intervention, including an increase in ratings of prosocial behavior and a decrease in referrals in school, some may erroneously conclude that, overall, students generally responded to the intervention, and the intervention could be used as described in the treatment manual as a somewhat effective tier two intervention for behavior. However, this conclusion overlooks the powerful interaction effects that were observed. The analysis results and the graphs clearly show a difference in response based on identified function. Only the students with attention-maintained behavior had significant improvements in all three dependent measures. In fact, the ratings of problem behavior of students with escape-maintained behavior increased during the intervention. It is unknown whether the increase in problem behavior was due to any possible harmful effects of the intervention or if it was related to neglecting to intervene based on students' negative academic experiences.

These results point to a critical role of function of problem behavior in behavioral interventions. Function appears to act as a moderator of the effects of a number of different behavioral interventions (Carter \& Horner, in press; Filter \& Horner, in press; Ingram et al., 2005; March \& Horner, 2002; Newcomer \& Lewis, 2004). The mechanisms underlying this link are clear when considering the structural components of an intervention. Check-In/Check-Out is designed to provide students with high rates of attention for appropriate behavior. Students are provided regularly scheduled opportunities to access attention by exhibiting appropriate behavior as opposed to problem behavior. Students whose behavior is maintained by escape from academic tasks may choose to exhibit appropriate behavior (especially if they also find attention reinforcing), but this choice does not provide escape from aversive academic task demands, the underlying maintaining consequence for problem behavior. An intervention that addresses escape-maintained behavior directly would include providing academic assistance, easier tasks, or momentary escape from tasks.

Overall, these results replicate and extend the findings of March and Horner (2002) and Carter and Horner (in press), who found a lack of positive effects for students with escape-maintained behavior and implemented tier three function-based support interventions for these students. This study adds to this literature by documenting these effects with a larger sample size and psychometrically sound measurement, as well as use within a three-tier RTI model. It still remains unknown whether the participants from those studies or this study (a) required the additional support of a tier three intervention, (b) could have been successful with a different tier two intervention, perhaps an academic intervention to address skill deficits (e.g., Lee, Sugai, \& Horner, 1999), or (c) could have been successful if the initial tier two intervention had been modified to address escape-maintained behavior.

Implications for practice. These results strongly suggest that school personnel would do well to avoid the "one-trick pony" phenomenon, in which a single tier two intervention is selected and applied in the same manner to all students needing support, regardless of their individual needs. There is a distinct analogy to tier two academic interventions as well-school personnel would not find success providing an effective fluency-building intervention to all struggling readers, in particular with those who need remediation in decoding (Haring, Lovitt, Eaton, \& Hansen, 1978). There is an emerging view in the field that there exists the need for multiple tier two interventions in both academic and behavior support. It is even more critical when considering that special education eligibility may be determined from response to a tier two intervention. In this case, a lack of student response to a tier two intervention may be misconstrued as evidence of a disability when an equally likely explanation may be that 
there was a poor match between the intervention and the function of the student's behavior.

This study identified function as one variable that deserves consideration in determining what tier two intervention to apply. For students whose identified function is escape from academic tasks, the Check-In/Check-Out intervention, delivered without any adjustments, may be a poor match to student needs. A promising approach includes a quick screening for function of problem behavior, such as the FACTS for students in general education or the Questions About Behavioral Function (Matson \& Vollmer, 1995), a rating scale for students with more severe needs, and then one of two options: (a) select the best match from a number of ongoing tier two interventions in the school (Oregon Department of Education, 2005), or (b) modify the intervention to provide effective support for students with escape-maintained behavior. Crone et al. (2003) describe modifications that may be made to adjust the Check-In/Check-Out to enhance effects for these students, such as providing the opportunity to earn reductions in academic work.

Moreover, this article documented the use of a tier two intervention within the context of a district implementing tiers one and three with fidelity. The article described the utility of a tier two intervention as an efficient, ongoing system to bridge the gap between universal and individual levels of support. The tier one intervention (SWPBS) reduced the number of students requiring a tier two intervention to a manageable level (McIntosh, Chard, Boland, $\&$ Horner, 2006). The tier three intervention (individualized function-based support) provided an additional level of intervention for students who needed more than the tier two intervention (Lewis-Palmer et al., 2004). Implementing a tier two intervention without tiers one and three in place would seem to be ill-advised, given how these tiers work to provide a continuum of support to students (Fairbanks et al., 2007).

Finally, this study highlighted the expanding role of school counselors and school social workers in providing and coordinating systems-level practices in schools in place of one-on-one counseling. The counselors who coordinated the programs in their schools were also members of the universal SWPBS committee, taught school-wide expectations and universal social skills, and facilitated functional behavior assessment and support planning in their schools. Counselors and social workers often have more flexibility at the start and end of the day than classroom teachers, and they may serve fewer schools than specialists such as behavior consultants or school psychologists, allowing for a direct connection to daily programming and troubleshooting. Hence, the school counselor, in addition to the school psychologist and teacher, can play a vital role in the three-tier RTI model.
Limitations. This study had several major limitations that the authors caution the readers to consider when interpreting the results. First, the study's design rests on accurate assignment to groups, and the assessment of function was not validated through direct observation or functional analysis. Although the measure used has evidence of validity and reliability under the conditions in this study (trained and experienced graduate students working with respondents knowledgeable about the students and their behavior; McIntosh, Borgmeier, et al., 2008), there still exists the possibility that the functions generated by the FACTS may have been inaccurate. Second, the dependent variables were also indirect measures of behavior. Although the use of a contemporary standardized behavior rating scale provides benefits over measurement with office discipline referrals, neither are as valid as direct observation of behavior. Third, the pre-post quasi-experimental design employed did not control for some threats to internal validity (such as time). This is less relevant for assessing the interaction effects, where a differential response was hypothesized. And fourth, the sample size, although large for studies considering function, is small for group designs. Thus, the exploration of only two functions and the ethnically homogeneous sample may not allow the results to be generalized to all students. As such, more research is needed to replicate the results of this study.

Further research. Direct and systematic replication of this study with other participant groups and settings will allow for improved external validity and generalization of results. Replication should include larger participant samples, students from diverse backgrounds, different age groups, teachers and interventionists with different skill levels, and students with varying educational and behavioral needs. Replication and extension of this study should also focus on the extent to which these results are applicable to other tier two behavioral interventions. With the goal of providing a continuum of effective, evidencebased behavioral interventions to students with problem behavior, it will be beneficial to assess the differential effects of various tier two interventions on the social behavior of students based on function of behavior.

Further research should focus not only on replication and extension of the effects of function of behavior on RTI but also on examining the applicability of including a quick screening for the function of problem behavior in schools prior to selecting and implementing tier two behavioral interventions. Research should address the effectiveness and efficiency of using quick function screenings to (a) modify existing tier two interventions to provide function-based support and (b) select interventions that match the identified function of behavior. In 
particular, research should explore the ability of school teams to identify the function of students' problem behavior and effectively match or modify tier two interventions to provide function-based support. By examining systems for providing function-based tier two behavioral interventions, school personnel will be more successful in identifying students who require tier three support and using the second tier of a comprehensive RTI model.

\section{References}

Beaver, B., \& Busse, R. T. (2000). Informant reports: Conceptual and research bases of interviews with parents and teachers. In E. S. Shapiro \& T. R. Kratochwill (Eds.), Behavioral assessment in the schools: Conceptual foundations and practical applications (2nd ed., pp. 257-287). New York: Guilford.

Borgmeier, C. (2003). An evaluation of informant confidence ratings as a predictive measure of the accuracy of hypotheses from functional assessment interviews. Unpublished doctoral dissertation, University of Oregon.

Bradley, R., Doolittle, J., Lopez, F., Smith, J., \& Sugai, G. (2007, January). Discipline: Improved understanding and implementation. OSEP Part B Regulations Regional Implementation Meeting: Building the Legacy IDEA 2004, Washington, DC.

Carr, E. G., Horner, R. H., Turnbull, A., Marquis, J., MagitoMcLaughlin, D., McAtee, M., et al. (1999). Positive behavior support as an approach for dealing with problem behavior in people with developmental disabilities: A research synthesis. Washington, DC: American Association on Intellectual and Developmental Disabilities.

Carr, E. G., Langdon, N. A., \& Yarbrough, S. (1999). Hypothesisbased intervention for severe problem behavior. In A. C. Repp \& R. H. Horner (Eds.), Functional analysis of problem behavior: From effective assessment to effective support (pp. 9-31). Belmont, CA: Wadsworth.

Carter, D. R., \& Horner, R. H. (2007). Adding function-based behavioral support to First Step to Success: Combining manualized and function-based interventions. Manuscript submitted for publication.

Carter, D. R., \& Horner, R. H. (in press). Adding functional behavioral assessment to First Step to Success: A case study. Journal of Positive Behavior Interventions.

Chafouleas, S. M., Riley-Tillman, T. C., \& McDougal, J. (2002). Good, bad, or in-between: How does the daily behavior report card rate? Psychology in the Schools, 39, 157-169.

Colvin, G., Kame'enui, E. J., \& Sugai, G. (1993). Reconceptualizing behavior management and school-wide discipline in general education. Education and Treatment of Children, 16, 361-381.

Crone, D. A., \& Horner, R. H. (2003). Building positive behavior support systems in schools: Functional behavioral assessment. New York: Guilford.

Crone, D. A., Horner, R. H., \& Hawken, L. S. (2003). Responding to problem behavior in schools: The Behavior Education Program. New York: Guilford.

Eber, L., Sugai, G., Smith, C. R., \& Scott, T. M. (2002). Wraparound and positive behavioral interventions and supports in the schools. Journal of Emotional and Behavioral Disorders, 10, 171-180.

Fairbanks, S., Sugai, G., Guardino, D., \& Lathrop, M. (2007). Response to intervention: An evaluation of a classroom system of behavior support for second grade students. Exceptional Children, 73, 288-310.
Filter, K. J., \& Horner, R. H. (in press). Functionally-indicated academic interventions for problem behavior. Journal of Positive Behavior Interventions.

Filter, K. J., McKenna, M. K., Benedict, E., Horner, R. H., Todd, A. W., \& Watson, J. (2007). Check-In/Check-Out: A post-hoc evaluation of an efficient, secondary-level targeted intervention for reducing problem behaviors in schools. Education and Treatment of Children, 30, 69-84.

Fuchs, D., Mock, D., Morgan, P. L., \& Young, C. L. (2003). Responsiveness-to-intervention: Definitions, evidence, and implications for the learning disabilities construct. Learning Disabilities Research \& Practice, 18, 157-171.

Gordon, R. S. (1983). An operational classification of disease prevention. Public Health Reports, 98, 107-109.

Gottfredson, G. D., \& Gottfredson, D. C. (1999). Development and application of theoretical measures for evaluating drug and delinquency prevention programs: Technical manual for research editions of What About You (WAY). Ellicott City, MD: Gottfredson Associates.

Gresham, F. M. (1991). Conceptualizing behavior disorders in terms of resistance to intervention. School Psychology Review, 20, 23-36.

Gresham, F. M. (2003). Establishing the technical adequacy of functional behavioral assessment: Conceptual and measurement challenges. Behavioral Disorders, 28, 282-298.

Gresham, F. M., VanDerHeyden, A., \& Witt, J. C. (2005). Response to intervention in the identification of learning disabilities: Empirical support and future challenges. Unpublished manuscript. Retrieved from http://www.joewitt.org/Downloads/ ResponsetoInterventionMSGreshamVanderheydenWitt.pdf

Haring, N. G., Lovitt, T. C., Eaton, M. D., \& Hansen, C. L. (1978). The fourth R: Research in the classroom. Columbus, $\mathrm{OH}$ : Merrill.

Hawken, L. S. (2006). School psychologists as leaders in the implementation of a targeted intervention: The Behavior Education Program. School Psychology Quarterly, 21, 91-111.

Hawken, L. S., \& Horner, R. H. (2003). Evaluation of a targeted group intervention within a school-wide system of behavior support. Journal of Behavioral Education, 12, 225-240.

Hawken, L. S., McLeod, K. S., \& Rawlings, L. (2007). Effects of the Behavior Education Program (BEP) on office discipline referrals of elementary school students. Journal of Positive Behavior Interventions, 9, 94-101.

Horner, R. H., Sugai, G., Todd, A. W., \& Lewis-Palmer, T. (2005). School-wide positive behavior support. In L. Bambara \& L. Kern (Eds.), Individualized supports for students with problem behaviors: Designing positive behavior plans (pp. 359-390). New York: Guilford.

Horner, R. H., Todd, A. W., Lewis-Palmer, T., Irvin, L. K., Sugai, G., \& Boland, J. B. (2004). The School-wide Evaluation Tool (SET): A research instrument for assessing school-wide positive behavior support. Journal of Positive Behavior Interventions, 6, 3-12.

Individuals with Disabilities Education Improvement Act, 20 U.S.C. $\S 1400$ (2004).

Ingram, K., Lewis-Palmer, T., \& Sugai, G. (2005). Function-based intervention planning: Comparing the effectiveness of FBA function-based and non-function-based intervention plans. Journal of Positive Behavior Interventions, 7, 224-236.

Irvin, L. K., Tobin, T. J., Sprague, J. R., Sugai, G., \& Vincent, C. G. (2004). Validity of office discipline referral measures as indices of school-wide behavioral status and effects of school-wide behavioral interventions. Journal of Positive Behavior Interventions, 6, 131-147.

Keppel, G., \& Zedeck, S. (1989). Data analysis for research designs. New York: Freeman. 
Lane, K. L., Umbreit, J., \& Beebe-Frankenberger, M. E. (1999). Functional assessment research on students with or at risk for EBD: 1990 to the present. Journal of Positive Behavior Interventions, 1, 101-111.

Lee, Y., Sugai, G., \& Horner, R. H. (1999). Using an instructional intervention to reduce problem and off-task behaviors. Journal of Positive Behavior Interventions, 1, 195-204.

Lewis-Palmer, T., Bounds, M., \& Sugai, G. (2004). Districtwide system for providing individual student support. Assessment for Effective Intervention, 30, 53-65.

Lewis-Palmer, T., Todd, A. W., Horner, R. H., Sugai, G., \& Sampson, N. K. (2003). Individual Student Systems Evaluation Tool (ISSET). Eugene, OR: Educational and Community Supports.

March, R. E., \& Horner, R. H. (2002). Feasibility and contributions of functional behavioral assessment in schools. Journal of Emotional and Behavioral Disorders, 10, 158-170.

March, R. E., Horner, R. H., Lewis-Palmer, T., Brown, D., Crone, D., Todd, A. W., et al. (2000). Functional Assessment Checklist for Teachers and Staff (FACTS). Eugene, OR: Educational and Community Supports. Available from http://www.pbis.org/tools.htm

Matson, J. L., \& Vollmer, T. (1995). User's guide: Questions About Behavioral Function $(Q A B F)$. Baton Rouge, LA: Scientific Publishers.

May, S., Ard, W. I., Todd, A. W., Horner, R. H., Glasgow, A., Sugai, G., et al. (2002). School-Wide Information System. Educational and Community Supports, University of Oregon, Eugene.

McIntosh, K., Borgmeier, C., Anderson, C. M., Horner, R. H., Rodriguez, B. J., \& Tobin, T. J. (2008). Technical adequacy of the Functional Assessment Checklist: Teachers and Staff (FACTS) FBA interview measure. Journal of Positive Behavior Interventions, 10, 33-45.

McIntosh, K., Brown, J. A., \& Borgmeier, C. J. (in press). Validity of functional behavior assessment within an RTI framework: Evidence and future directions. Assessment for Effective Intervention.

McIntosh, K., Chard, D. J., Boland, J. B., \& Horner, R. H. (2006). Demonstration of combined efforts in school-wide academic and behavioral systems and incidence of reading and behavior challenges in early elementary grades. Journal of Positive Behavior Interventions, 8, 146-154.

McIntosh, K., Campbell, A. L., Carter, D. R., \& Zumbo, B. D. (2008). Relations among informal, standardized, and functional behavior measures: ODRs, suspensions, BASC-2, and FACTS. Manuscript in preparation.

Newcomer, L. L., \& Lewis, T. J. (2004). Functional behavioral assessment: An investigation of assessment reliability and effectiveness of function-based interventions. Journal of Emotional and Behavioral Disorders, 12, 168-181.

Oregon Department of Education. (2005). Identification of students with learning disabilities under the IDEA 2004: Oregon Response to Intervention. Salem: Oregon Department of Education. Retrieved from http://www.ode.state.or.us/search/results/?id=319

O'Shaughnessy, T. E., Lane, K., Gresham, F. M., \& BeebeFrankenberger, M. E. (2003). Children placed at risk for learning and behavioral difficulties: Implementing a school-wide system of early identification and intervention. Remedial and Special Education, 24, 27-35.

Reynolds, C. R., \& Kamphaus, R. W. (2004). Behavior Assessment Scale for Children (2nd ed.). Circle Pines, MN: AGS Publishing.
Sasso, G. M., Conroy, M. A., Stichter, J. P., \& Fox, J. J. (2001). Slowing down the bandwagon: The misapplication of functional assessment for students with emotional or behavioral disorders. Behavioral Disorders, 26, 282-296.

Simeonsson, R. J. (Ed.). (1994). Risk, resilience \& prevention: Promoting the well-being of all children. Baltimore: Paul H. Brooks.

Simmons, D. C., Kame'enui, E. J., Good, R. H., Harn, B. A., Cole, C., \& Braun, D. (2002). Building, implementing, and sustaining a beginning reading model: Lessons learned school by school. In M. R. Shinn, H. M. Walker, \& G. Stoner (Eds.), Interventions for academic and behavioral problems II: Preventive and remedial approaches (pp. 403-432). Bethesda, MD: National Association of School Psychologists.

Sugai, G., Horner, R. H., Dunlap, G., Hieneman, M., Lewis, T. J., Nelson, C. M., et al. (2000). Applying positive behavior support and functional behavioral assessment in schools. Journal of Positive Behavior Interventions, 2, 131-143.

Sugai, G., Horner, R. H., \& Gresham, F. M. (2002). Behaviorally effective school environments. In M. R. Shinn, H. M. Walker, \& G. Stoner (Eds.), Interventions for academic and behavior problems II: Preventive and remedial approaches (pp. 315-350). Bethesda, MD: National Association of School Psychologists.

Sugai, G., Sprague, J. R., Horner, R. H., \& Walker, H. M. (2000). Preventing school violence: The use of office discipline referrals to assess and monitor school-wide discipline interventions. Journal of Emotional and Behavioral Disorders, 8, 94-101.

Sugai, G., Lewis-Palmer, T. L., Todd, A. W., \& Horner, R. H. (2001). School-wide Evaluation Tool (SET). Eugene, OR: Educational and Community Supports. Available at http://www.pbis.org

Tobin, T. J., \& Sugai, G. M. (1999). Using sixth-grade school records to predict school violence, chronic discipline problems, and high school outcomes. Journal of Emotional and Behavioral Disorders, 7, 40-53.

Todd, A. W., Campbell, A. L., Meyer, G. G., \& Horner, R. H. (2008). The effects of a targeted intervention to reduce problem behaviors: Elementary school implementation of Check In-Check Out. Journal of Positive Behavior Interventions, 10, 46-55.

Vaughn, S., Linan-Thompson, S., \& Hickman, P. (2003). Response to instruction as a means of identifying students with reading/learning disabilities. Exceptional Children, 69, 391-409.

Walker, B., Cheney, D., Stage, S. A., \& Blum, C. (2005). Schoolwide screening and positive behavior supports: Identifying and supporting students at risk for school failure. Journal of Positive Behavior Interventions, 7, 194-204.

Walker, H. M., Horner, R. H., Sugai, G., Bullis, M., Sprague, J. R., Bricker, D., et al. (1996). Integrated approaches to preventing antisocial behavior patterns among school-age children and youth. Journal of Emotional and Behavioral Disorders, 4, 194-209.

Walker, H. M., Kavanagh, K., Stiller, B., Golly, A., Severson, H., \& Feil, E. G. (1998). First Step to Success: An early intervention approach for preventing school antisocial behavior. Journal of Emotional and Behavioral Disorders, 6, 66-80.

Kent McIntosh, $\mathrm{PhD}$, is an assistant professor of school psychology at the University of British Columbia. His current research interests include sustainability of school-wide positive behavior support, functional behavior assessment, and academic and behavioral systems change. 
Amy L. Campbell, PhD, is an assistant professor of psychology at Grand Valley State University. Her current research interests include targeted interventions, functional behavior assessment, and tertiary level behavior support systems.

Deborah Russell Carter, $\mathrm{PhD}$, is an assistant professor of special education at Boise State University. Her current research interests include program-wide positive behavior support in early childhood settings, family involvement, and early literacy development.

Celeste Rossetto Dickey, MEd, is a courtesy research assistant at the University of Oregon and positive behavior support (PBS) consultant for the Bethel School District. Her interests include School-Wide Positive Behavior Support (SWPBS) and working with states, districts, and schools on SWPBS implementation. 